\title{
Glaze Icing on Superhydrophobic Coating Prepared by Nanoparticles Filling Combined with Etching Method for Insulators
}

\author{
Chao Guo, ${ }^{1}$ Ruijin Liao, ${ }^{1}$ Yuan Yuan, ${ }^{2}$ Zhiping Zuo, ${ }^{1}$ and Aoyun Zhuang ${ }^{1}$ \\ ${ }^{1}$ State Key Laboratory of Power Transmission Equipment \& System Security and New Technology, Chongqing University, \\ Chongqing 400044, China \\ ${ }^{2}$ College of Materials Science and Engineering, Chongqing University, Chongqing 400044, China
}

Correspondence should be addressed to Ruijin Liao; rjliao@cqu.edu.cn

Received 5 September 2014; Accepted 18 November 2014

Academic Editor: Jiamin Wu

Copyright (C) 2015 Chao Guo et al. This is an open access article distributed under the Creative Commons Attribution License, which permits unrestricted use, distribution, and reproduction in any medium, provided the original work is properly cited.

\begin{abstract}
Icing on insulators may cause flashover or even blackout accidents in the power transmission system. However, there are few anti-icing techniques for insulators which consume energy or manpower. Considering the water repelling property, the superhydrophobic surface is introduced for anti-icing of insulators. Among the icing forms, the glaze icing owns the highest density, strongest adhesion, and greatest risk to the power transmission system but lacks researches on superhydrophobic surface. In this paper, superhydrophobic surfaces with contact angle of $166.4^{\circ}$, contact angle hysteresis of $0.9^{\circ}$, and sliding angle of less than $1^{\circ}$ are prepared by nanoparticle filling combined with etching method. The coated glass slide and glass insulator showed excellent anti-icing performance in the glaze icing test at $-5^{\circ} \mathrm{C}$. The superhydrophobicity and anti-icing property of the coatings benefit from the low surface energy and hierarchical rough structure containing micron scale pits and nanoscale coralloid bulges supported by scanning electron microscopy (SEM), atomic force microscopy (AFM), and X-ray photoelectron spectroscopy (XPS) characterization.
\end{abstract}

\section{Introduction}

Icing is a global problem causing tremendous economic losses, equipment failures, and casualties. In 2008, the icing in southern China resulted in outage of 36740 power transmission lines and 1743 substations with 2 billion dollars of direct economic loss [1]. The icing accumulation on insulators and transmission lines caused line breakage, conductor galloping, falling down of transmission tower, and insulator flashover, further leading to power blackout. Techniques for anti-icing and deicing of transmission lines have been well developed like current deicing [2], deicing robot [3], ferromagnetic wires [4], and electromagnetic-impulsive deicing [5]. However, these methods consume a lot of energy and cannot be applied on insulators whose anti-icing and deicing techniques are very limited. Liao et al. [6] introduced the semiconducting RTV silicone coating on insulators to generate Joule heat to reduce the ice formation which however still costs energy and accelerates the aging of the coating. The superhydrophobic surface is an efficient anti-icing method as its water repelling property proved by many researches [7-9]. However, they mainly considered the frost formation or icing of static water drops on superhydrophobic surfaces [10,11]. As an important icing form, the glaze icing is most dangerous to the power transmission system because of its high density and adhesion whose accumulation on superhydrophobic surfaces lacks attention. There are three kinds of insulators in the power transmission system which are the glass insulator, the ceramic insulator, and the composite insulator. The glass insulator is widely utilized in the State Grid of China with a ratio of $23.9 \%$ up to 2007. Therefore, the glass slides and glass insulators were chosen as the coating substrates.

There are many methods to fabricate superhydrophobic surfaces like sol-gel [12], physical vapor deposition [13], chemical vapor deposition [14], lithography [15], and phase separation [16]. However, most methods are expensive and 
complicated which are not suitable for industry application on insulators. In the previous research, the application of silica, calcium carbonate, fluorosilicone resin, and epoxy in superhydrophobic surfaces have been explored while the combination of nanoparticles filling and etching methods seems rare. For instance, Zhang et al. fabricated superhydrophobic surface with a mixture of nano- and microsized calcium carbonate $\left(\mathrm{CaCO}_{3}\right)$ suspensions [17]. Hydrophobic surfaces were prepared on epoxy coating surfaces by using fluorosilicone copolymer and $\mathrm{SiO}_{2}$ nanoparticles [18]. In this paper, a facile approach combining the nanoparticle filling and the etching method to fabricate superhydrophobic coating is proposed. The wettability, surface morphology, and chemical construction of the coatings are characterized. In particular, the glaze icing properties of coatings on glass slides and glass insulators are investigated in the artificial climate chamber.

\section{Experimental}

2.1. Preparation. The glass slides were ultrasonically cleaned in absolute ethanol and distilled water and then dried before used as substrates. The fluoroalkylsilane ( $2 \mathrm{~mL}, \mathrm{G} 502$, $\mathrm{C}_{14} \mathrm{~F}_{12} \mathrm{H}_{20} \mathrm{SiO}_{3},>95 \%$ ), distilled water (4 g) and ethanol $(200 \mathrm{~mL})$ were added into a flask. The mixed solution was stirred at $240 \mathrm{r} / \mathrm{min}$ and $60^{\circ} \mathrm{C}$ for $30 \mathrm{~min}$ before nanometer calcium carbonate $(10 \mathrm{~g}, 30-60 \mathrm{~nm})$ was added. $150 \mathrm{~mL}$ of upper clear liquid was removed after 15 minutes' standing. Then nanosilica particles $(10 \mathrm{~g}, 15-25 \mathrm{~nm}$, Henan Wangwu Technology Co., Ltd.) and ethyl acetate $(90 \mathrm{~mL})$ were added into the solution and stirred for another $30 \mathrm{~min}$. Finally $130 \mathrm{~g}$ of solution containing nanometer calcium carbonate (10 g) and nanosilica particles (10 g) was obtained. The asprepared nanoparticles were filled in polymers consisted of fluorosilicon resin (FSI, fluorinated organosilicon resin with contact angle of $110^{\circ}$, Ark Chemicals Industry Co. Ltd) and epoxy resin (E-51). Three coatings were fabricated by adjusting the contents of nanoparticles (20\%, 33\%, and 49\%). The mass ratio among nano- $\mathrm{CaCO}_{3}$, nano- $\mathrm{SiO}_{2}, \mathrm{FSI}, \mathrm{E}-51$, curing agent, and solvent was $1: 1: 6: 1.2: 1: 11$ for the coating with nanoparticle content of $20 \%$. The mixed solution was dispersed by electromagnetic stirring and ultrasonic agitation before spray coating. The spraying distance between the nozzle and the substrates was $25 \mathrm{~cm}$ and the air pressure was held at $0.4 \mathrm{MPa}$. The nozzle was fixed and the substrates moved with a speed of $2 \mathrm{~cm} / \mathrm{s}$. The substrates were sprayed for 4 times and then dried at $130^{\circ} \mathrm{C}$ for $30 \mathrm{~min}$. The coatings were then immersed into acetic acid for $10 \mathrm{~s}$ and then put into abundant distilled water for etching. Finally, these samples were dried at $130^{\circ} \mathrm{C}$ for $30 \mathrm{~min}$ before characterization. The glass insulators (FC70/146, Huayu HV Insulator Co. Ltd.) were treated in the same way as the glass slides.

2.2. Characterization. The wettability of the samples was evaluated using an optical contact angle meter (Drop Meter A-200, MAIST Vision Inspection \& Measurement Co., Ltd.). The contact angle was observed by placing a $5 \mu \mathrm{L}$ droplet on the sample and five measurements were made for each sample. The contact angle hysteresis was measured by method of adding and decreasing the volume of the droplet. The surface morphologies of the samples were observed with the field emission scanning electron microscope (FESEM, S-4800, Hitachi Ltd., Japan). The surface topography of the samples was obtained by atomic force microscope (AFMIPC-208B, Chongqing University) using a tungsten probe (force constant $=0.06 \mathrm{~N} / \mathrm{m}$ ) operating in tapping mode in air at ambient conditions. The composition of the sample was analyzed using X-ray photoelectron spectrometry (XPS, Thermo escalab 250Xi, Thermo Fisher Scientific Inc., MA, USA) with $\mathrm{Al} \mathrm{K} \alpha \mathrm{X}$-ray source. The glaze icing experiment was conducted in the artificial climate chamber with temperature of $-5^{\circ} \mathrm{C}$ and relative humidity of $79 \pm 10 \%$. The rain was generated through a nozzle by pumping water of 3.8$5^{\circ} \mathrm{C}$ with volume median diameter of about $100 \mu \mathrm{m}$. The glass slides were set vertically facing the rain drops while the glass insulators were hanged.

\section{Results and Discussion}

The morphologies of the coatings before and after etching with particle content of $33 \%$ are presented in Figure 1. The surface is rather like that of moon with many ringlike pits or craters whose sizes range from 1 to $20 \mu \mathrm{m}$ in Figures 1(a) and 1(d). Observed in the nanoscale of Figures 1(c) and 1(f), the edges of the pits consist of nanometer coralloid bulges due to the addition of nanoparticles. This hierarchical rough structure is generated by the fast evaporation of the solvent when spraying. The mixture of resins (including fluorosilicone resin and epoxy resin), nanoparticles (including $\mathrm{SiO}_{2}$ and $\mathrm{CaCO}_{3}$ ), ethyl acetate, and ethyl alcohol is sprayed onto the glass with high speed leading to the fast evaporation of solvent, increase of the viscosity, and inhomogeneous distribution of the mixture. The bigger pits and smaller coralloid bulges are formed after the solidification of resins. However, the coatings before and after etching show little difference in the SEM images which need more accurate topological information.

The topological information of the surfaces is given in Figure 2. The coating after etching has rougher surface as the height difference between the peak and valley (1404 nm), Ra (at $y=3200 \mathrm{~nm}$ ), and Sa are all bigger. This may be caused by the etching of $\mathrm{CaCO}_{3}$ as shown in (1). The $\mathrm{CaCO}_{3}$ particles were reacted with acetic acid making the pits deeper and the surface rougher leading to the improvement of wettability. Consider

$$
2 \mathrm{CH}_{3} \mathrm{COOH}+\mathrm{CaCO}_{3} \longrightarrow\left(\mathrm{CH}_{3} \mathrm{COO}\right)_{2} \mathrm{Ca}+\mathrm{H}_{2} \mathrm{O}+\mathrm{CO}_{2}
$$

The XPS spectra of the coatings are illustrated in Figure 3. After etching, the peaks of $\mathrm{Ca} 2 \mathrm{~s}$ and $\mathrm{Ca} 2 \mathrm{p}$ almost disappear proving the reaction of $\mathrm{CaCO}_{3}$ with acetic acid. The increase of peaks of Si $2 s, \mathrm{Si} 2 \mathrm{p}, \mathrm{O}$ 1s, and F 1s may be caused by increase of content of resins and nanosilica as the etching of $\mathrm{CaCO}_{3}$. From Figure 4, the presence of $-\mathrm{CF}_{2}$ on the surface from the fluorosilicone resin can be confirmed indicating the low surface energy of the coating.

The wettability of the samples is given in Figure 5. The coatings showed excellent superhydrophobicity and achieved 


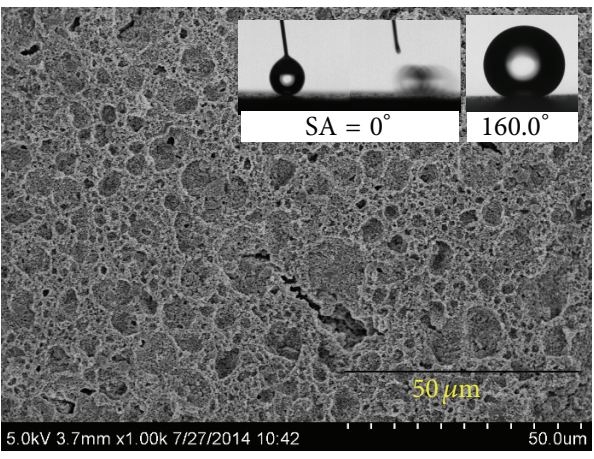

(a)

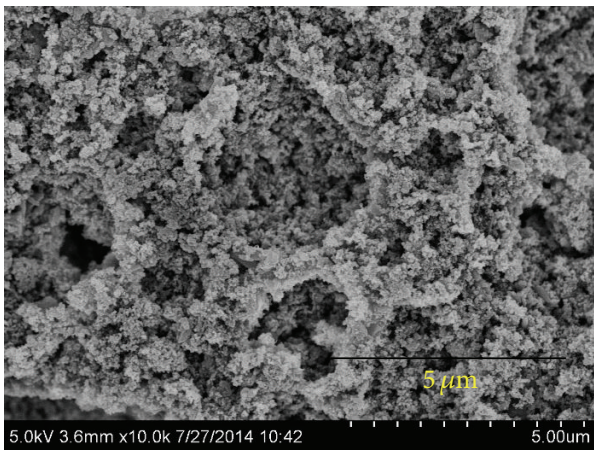

(b)

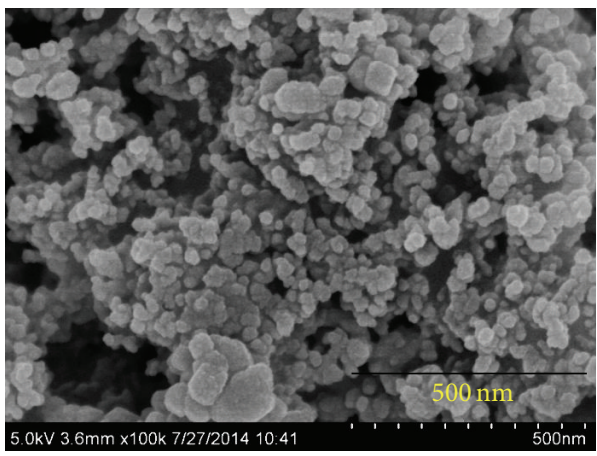

Before etching

(c)

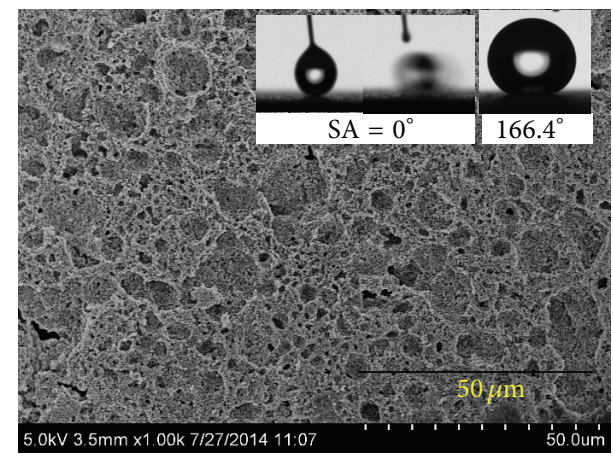

(d)

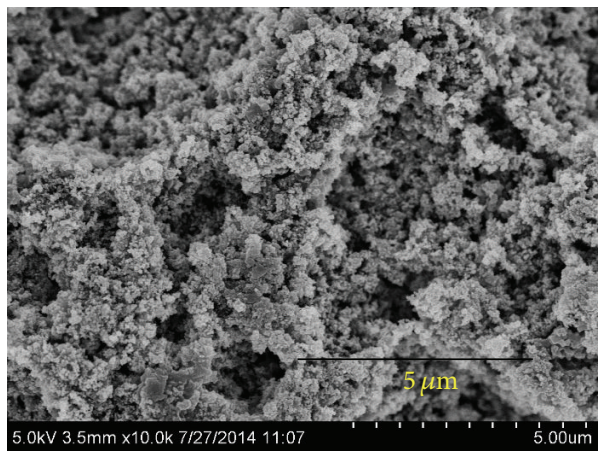

(e)

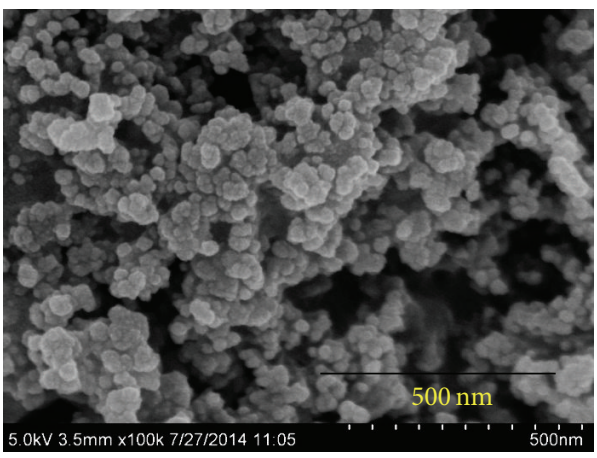

After etching

(f)

FIGURE 1: SEM images of coatings before (a)-(c) and after etching (d)-(f) with particle content of 33\%. The insets show the optical images of sliding angle and contact angle testing.

improvement after etching. The contact angle increases from $159^{\circ}$ up to $165^{\circ}$ with the increase of nanoparticles content before etching. However, coatings with smaller percentage of nanoparticles get bigger contact angles after etching. All the samples show sliding angle (SA) of less than $1^{\circ}$ illustrated by the insets of Figure 1 in which the water drops slide off the horizontal surface in few seconds. The contact angle hystereses of coatings decrease after etching and the lowest contact angle hysteresis is achieved by coatings with particle content of $33 \%$. As the dynamic wettability is more important in antiicing and etched surface shows better superhydrophobicity, etched coatings with particle content of $33 \%$ are chosen for glaze icing test and characterization.
The superhydrophobic property of the coating is due to the special rough structure and chemical composition of the surface [19]. The high contact angle is caused by the surface tension of water and air retained at the interface between water and the micro-/nanohierarchical structure. The low contact angle hysteresis and low sliding angle benefit from the rough structure and low surface energy. The friction of the water drop with the surface affects the sliding angle and contact angle hysteresis when the water drop starts to slide and is sliding, respectively. For the superhydrophobic surface in this paper, the friction of the water drop with the surface is small because the contact area and the adhesive force between them are small. 


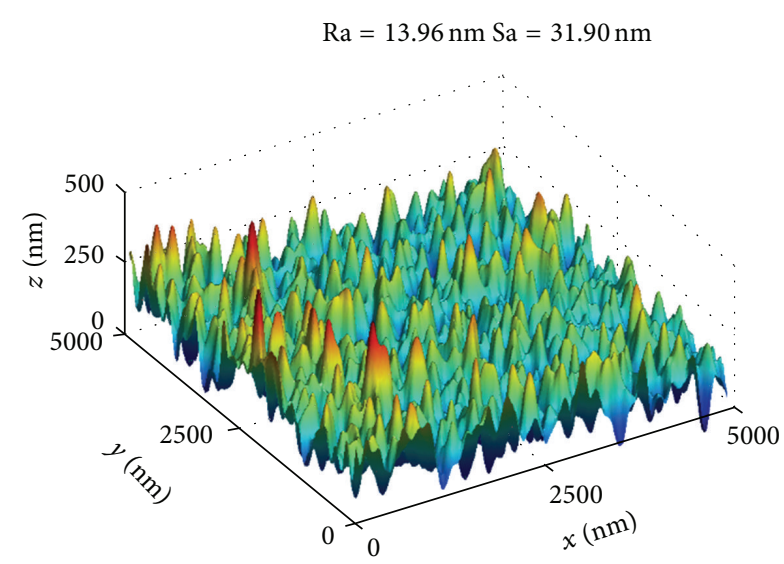

Before etching

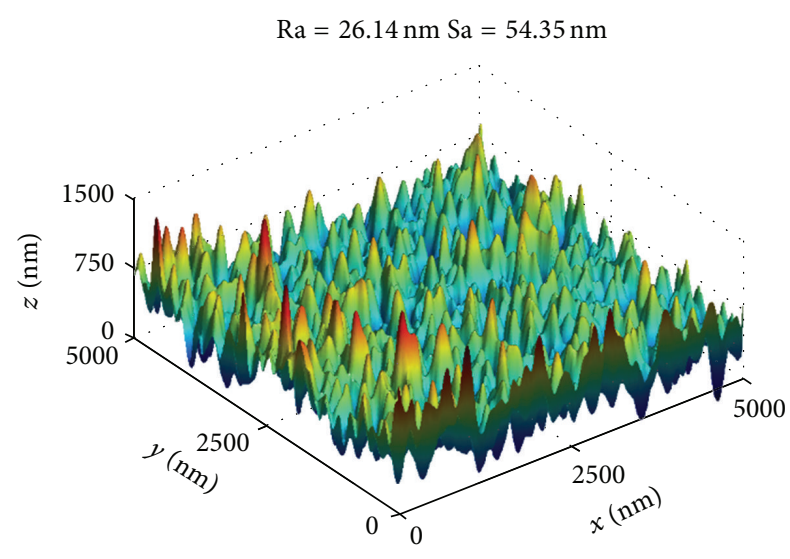

After etching

Figure 2: AFM images of coatings before and after etching with particle content of $33 \%$.

The schematic diagram and results of glaze icing test are shown in Figure 6. After 60 min of glaze icing, only $20 \%$ of the coated sample was covered with separated ice caused by the hydrophilic edge of the glass slide. On the contrary, the uncoated glass slide was covered fully by thick and transparent ice. This anti-icing property can be interpreted by the excellent superhydrophobicity of the coating. The hierarchical rough structure is beneficial to the repelling of freezing rain on the surface. As the diameter of freezing rain falls in certain range, smaller drops can be repelled by nanometer pillars and collide with each other to become bigger drops which can be repelled by micrometer-scale pits [20]. Fortunately, bigger water drops are difficult to loss their internal energy and become ice because they have relative less contact area with the surface and the cold air. High contact angle of $166.4^{\circ}$ indicates small contact area of the water drop with the surface. Meanwhile, low slide angle of less than $1^{\circ}$ and contact angle hysteresis of $0.9^{\circ}$ leads to the fast sliding of water drops on the surface which reduces the contact time of water drops with the surface. Therefore, reduced contact area and contact time of the water drops with the surface decrease the probability of heterogeneous nucleation of water and the

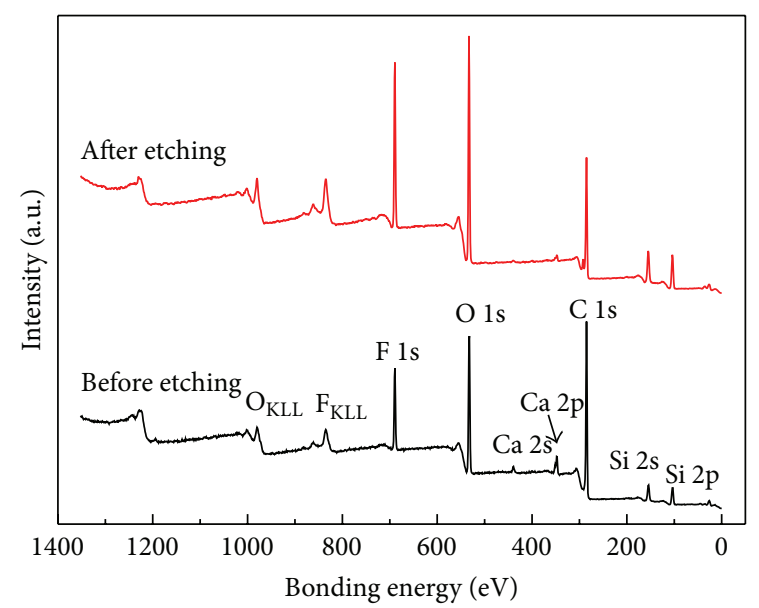

FIGURE 3: XPS images of coatings before and after etching with particle content of $33 \%$.

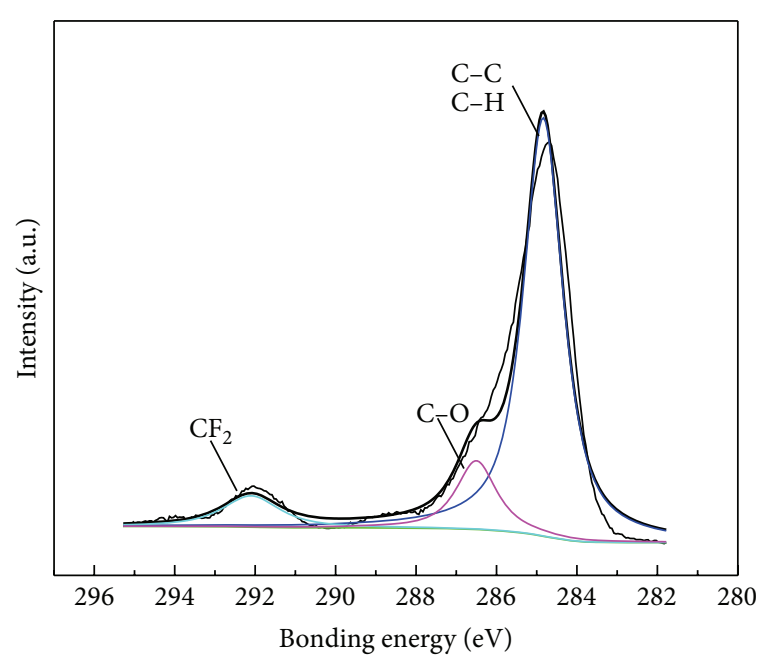

FIGURE 4: High revolution XPS of C 1s of coatings after etching with particle content of $33 \%$.

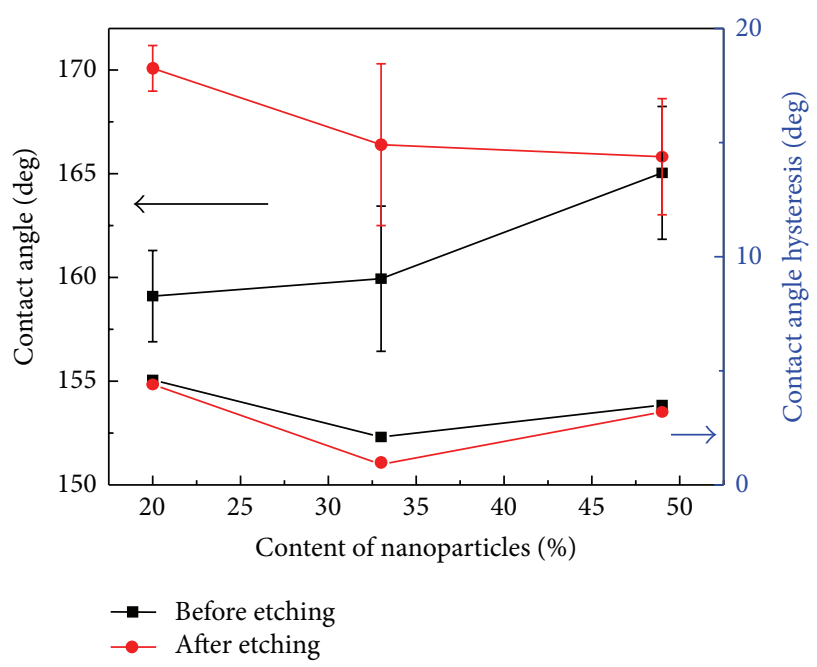

Figure 5: Wettablity of samples before and after etching varying with the content of nanoparticles. 


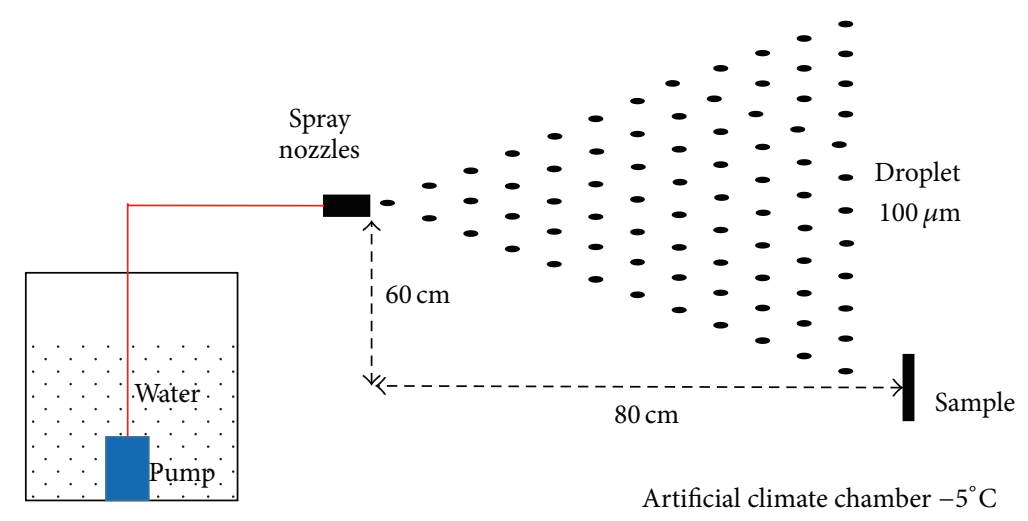

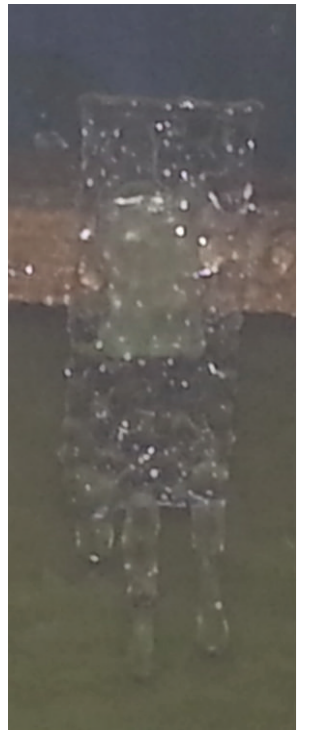

Uncoated

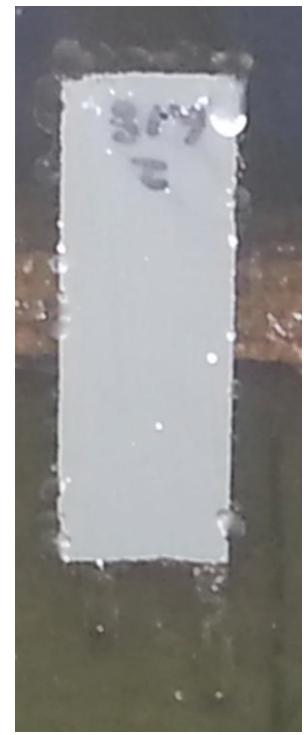

Coated

$$
t=15 \mathrm{~min}
$$

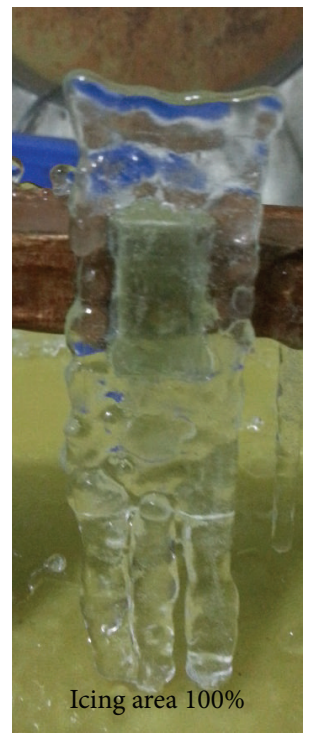

Uncoated

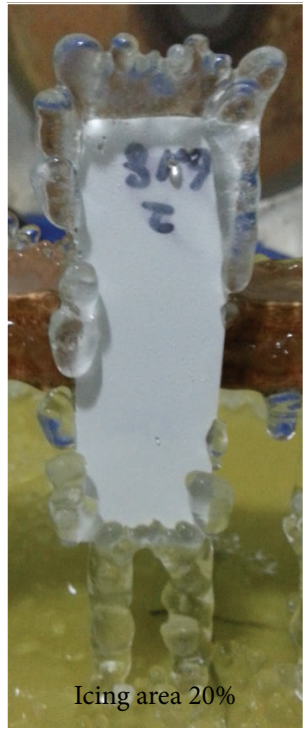

Coated

Figure 6: The schematic diagram of glaze icing test and glaze icing results of coated and uncoated glass slides at $t=15 \mathrm{~min}$ and $60 \mathrm{~min}$ (particle content $=33 \%$ ).

rate of heat transmission between the two phases of solid and liquid.

Similar results were received in the glaze icing test as shown in Figure 7. At the beginning of the test $(t=5 \mathrm{~min})$, the coated insulator had few separated water drops and ice particles as the water drops could bounce and slide off the insulator surface. At the end of the glaze icing test, only partial surface of the coated insulator was covered with separated ice particles and some unfrozen water drops. On the contrary, the uncoated and hydrophilic insulator was covered with thick ice which reduced the surface resistance and may lead to insulator flashover and power blackout in the power transmission system [21]. The anti-icing performance of the insulator is worse than the vertically placed glass slide as the tilting angle of the insulator surface is only about $15^{\circ}$ and the diameter is $255 \mathrm{~mm}$ which is rather larger than the size of the glass slides $(25 \mathrm{~mm} * 75 \mathrm{~mm})$. The contact time of the water drops with the coating is increased as the tilting angle is smaller and the distance is longer which leads to the increase of probability of heterogeneous nucleation and rate of heat transmission. In general, the superhydrophobic coating shows great potential in anti-icing of insulators in power transmission system.

\section{Conclusions}

Superhydrophobic coatings with contact angle of $166.4^{\circ}$, contact angle hysteresis of $0.9^{\circ}$, and sliding angle of less than $1^{\circ}$ are fabricated by nanoparticle filling combined with etching method when the particle content is $33 \%$. This coating on glass slide showed excellent anti-icing property with only $20 \%$ of surface area covered by glaze ice. Similarly, few parts of the coated insulator were covered with separated ice and unfrozen water drops. On the contrary, the uncoated glass slides and insulators were fully covered with thick ice. The excellent superhydrophobicity and anti-icing property 

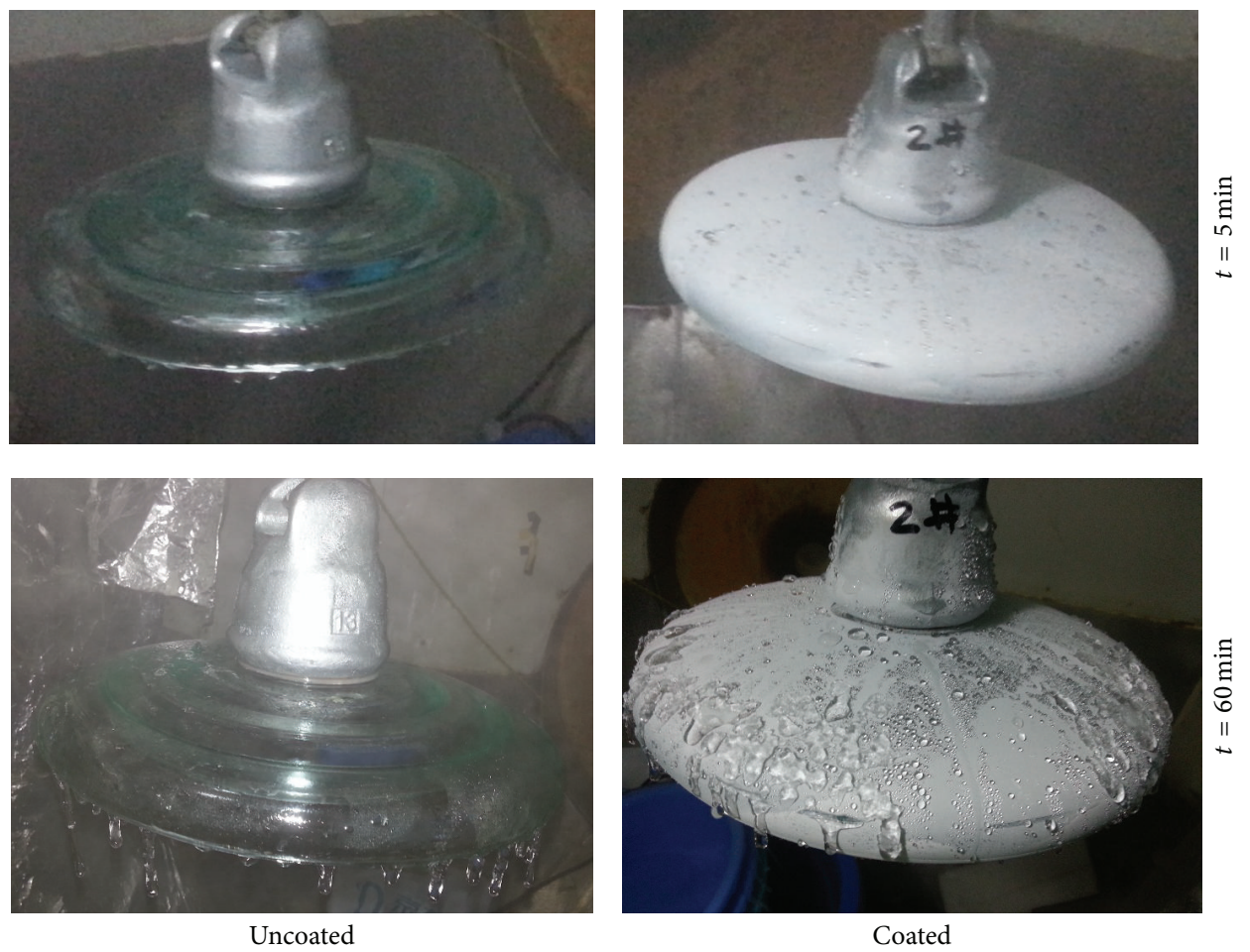

FIGURE 7: The glaze icing results of coated and uncoated glass insulators at $t=5 \mathrm{~min}$ and $60 \mathrm{~min}$ (particle content $=33 \%$ ).

are due to the hierarchical rough structure and low surface energy proved by the SEM, AFM, and XPS characterization.

\section{Conflict of Interests}

The authors declare that there is no conflict of interests regarding the publication of this paper.

\section{Acknowledgments}

This work is financially supported by the General Program of Natural Science Foundation of China (51377177) and Natural Science Foundation Project of CQ CSTC (cstcjjA50007).

\section{References}

[1] X. Wang, J. Hu, B. Wu, L. Du, and C. Sun, "Study on edge extraction methods for image-based icing on-line monitoring on overhead transmission lines," in Proceedings of the International Conference on High Voltage Engineering and Application (ICHVE '08), pp. 661-665, Chongqing, China, November 2008.

[2] M. Huneault, C. Langheit, R. St.-Arnaud, J. Benny, J. Audet, and J.-C. Richard, "A dynamic programming methodology to develop de-icing strategies during ice storms by channeling load currents in transmission networks," IEEE Transactions on Power Delivery, vol. 20, no. 2, pp. 1604-1610, 2005.

[3] J. Zhao, R. Guo, L. Cao, and F. Zhang, "Improvement of lineROVer: a mobile robot for de-icing of transmission lines," in Proceedings of the 1st International Conference on Applied Robotics for the Power Industry (CARPI '10), pp. 1-4, Montreal, Canada, October 2010.
[4] M. Yasui, K. Maekawa, Y. Naganuma et al., "Removal of icy snow accumulation on the transmission line by applying LC-spiral rod," Fujikura Technical Review, vol. 16, pp. 26-33, 1987.

[5] M. Farzaneh, C. Volat, and A. Leblond, Anti-Icing and De-Icing Techniques for Overhead Lines, Springer, New York, NY, USA, 2008.

[6] W. Liao, Z. Jia, Z. Guan et al., "Reducing ice accumulation on insulators by applying semiconducting RTV silicone coating," IEEE Transactions on Dielectrics and Electrical Insulation, vol. 14, no. 6, pp. 1446-1454, 2007.

[7] C. Antonini, M. Innocenti, T. Horn, M. Marengo, and A. Amirfazli, "Understanding the effect of superhydrophobic coatings on energy reduction in anti-icing systems," Cold Regions Science and Technology, vol. 67, no. 1-2, pp. 58-67, 2011.

[8] L. Mishchenko, B. Hatton, V. Bahadur, J. A. Taylor, T. Krupenkin, and J. Aizenberg, "Design of ice-free nanostructured surfaces based on repulsion of impacting water droplets," ACS Nano, vol. 4, no. 12, pp. 7699-7707, 2010.

[9] L. Ge, G. Ding, H. Wang, J. Yao, P. Cheng, and Y. Wang, "Antiicing property of superhydrophobic octadecyltrichlorosilane film and its ice adhesion strength," Journal of Nanomaterials, vol. 2013, Article ID 278936, 3 pages, 2013.

[10] J. B. Boreyko and C. P. Collier, "Delayed frost growth on jumping-drop superhydrophobic surfaces," ACS Nano, vol. 7, no. 2, pp. 1618-1627, 2013.

[11] J. Yang and W. Li, "Preparation of superhydrophobic surfaces on Al substrates and the anti-icing behavior," Journal of Alloys and Compounds, vol. 576, pp. 215-219, 2013.

[12] K. Tadanaga, J. Morinaga, A. Matsuda, and T. Minami, "Superhydrophobic-superhydrophilic micropatterning on flowerlike alumina coating film by the sol-gel method," Chemistry of Materials, vol. 12, no. 3, pp. 590-592, 2000. 
[13] C. Becker, J. Petersen, G. Mertz, D. Ruch, and A. Dinia, "High superhydrophobicity achieved on poly(ethylene terephthalate) by innovative laser-assisted magnetron sputtering," The Journal of Physical Chemistry C, vol. 115, no. 21, pp. 10675-10681, 2011.

[14] Y. Wu, M. Kouno, N. Saito, F. Andrei Nae, Y. Inoue, and O. Takai, "Patterned hydrophobic-hydrophilic templates made from microwave-plasma enhanced chemical vapor deposited thin films," Thin Solid Films, vol. 515, no. 9, pp. 4203-4208, 2007.

[15] J. Y. Shiu, C. W. Kuo, P. Chen, and C. Y. Mou, "Fabrication of tunable superhydrophobic surfaces by nanosphere lithography," Chemistry of Materials, vol. 16, no. 4, pp. 561-564, 2004.

[16] A. Nakajima, K. Abe, K. Hashimoto, and T. Watanabe, "Preparation of hard super-hydrophobic films with visible light transmission," Thin Solid Films, vol. 376, no. 1-2, pp. 140-143, 2000.

[17] H. Zhang, X. Zeng, Y. Gao, F. Shi, P. Zhang, and J.-F. Chen, "A facile method to prepare superhydrophobic coatings by calcium carbonate," Industrial and Engineering Chemistry Research, vol. 50, no. 6, pp. 3089-3094, 2011.

[18] R. Karmouch and G. G. Ross, "Superhydrophobic wind turbine blade surfaces obtained by a simple deposition of silica nanoparticles embedded in epoxy," Applied Surface Science, vol. 257, no. 3, pp. 665-669, 2010.

[19] R. Blossey, "Self-cleaning surfaces-Virtual realities," Nature Materials, vol. 2, no. 5, pp. 301-306, 2003.

[20] J. B. Boreyko and C.-H. Chen, "Self-propelled jumping drops on superhydrophobic surfaces," Physics of Fluids, vol. 22, no. 9, Article ID 091110, 2010.

[21] M. Farzaneh and J. Kiernicki, "Flashover problems caused by ice build-up on insulators," IEEE Electrical Insulation Magazine, vol. 11, no. 2, pp. 5-17, 1995. 

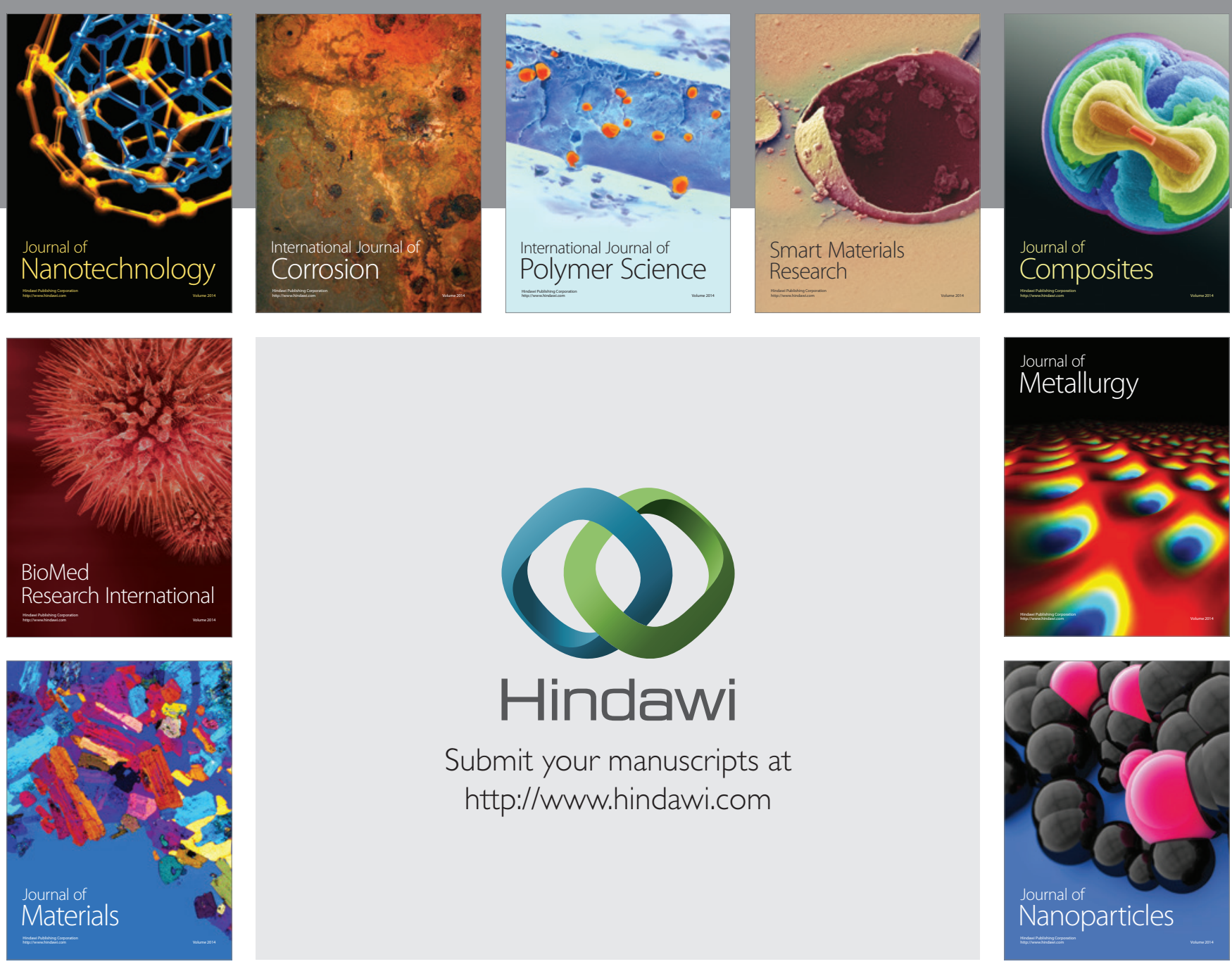

Submit your manuscripts at http://www.hindawi.com
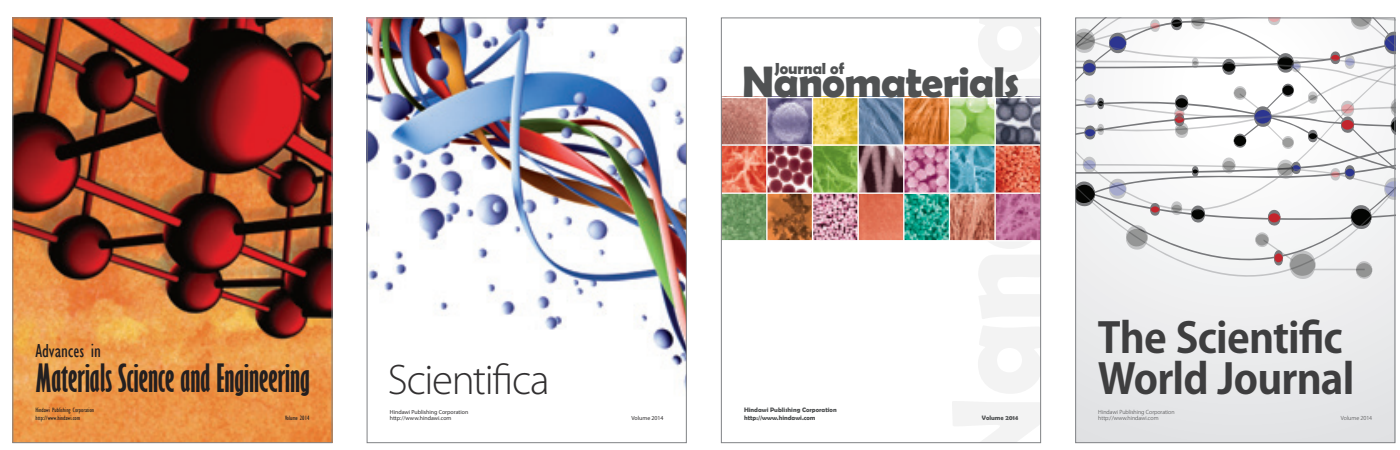

\section{The Scientific World Journal}
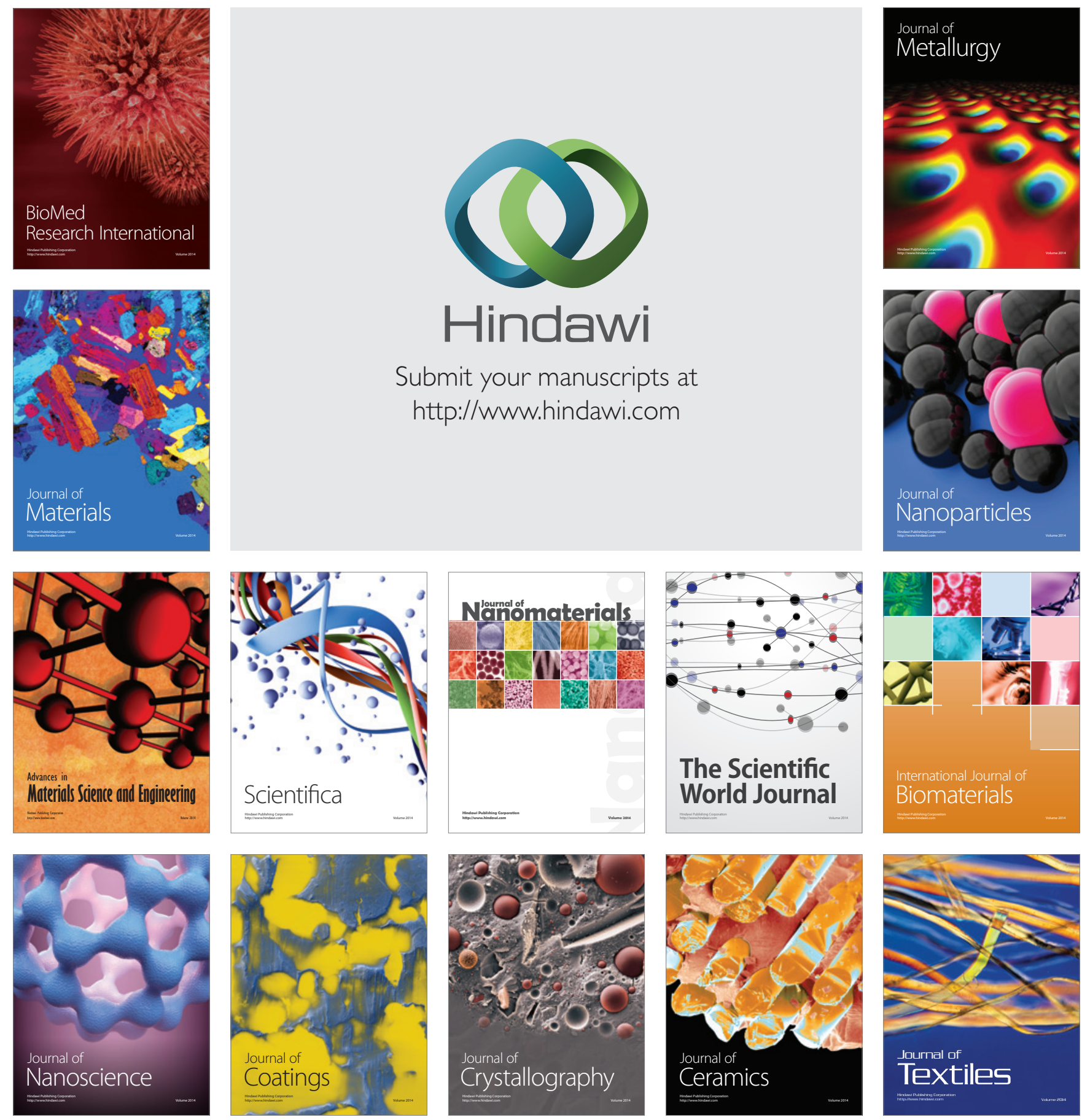